\title{
Clinical Study and Outcome of Polycystic Ovarian Syndrome
}

\author{
Gayatri Linganagouda Patil', Geeta Hosanemati' , L.S.Patil' ${ }^{2}$ Vijayanath.V ${ }^{3}$, \\ Venkatesh M Patil ${ }^{4}$, Rajeshwari. R. Surpur ${ }^{5}$ \\ Dept of Obs/Gyn', Dept of Surgical Oncology'2, Dept of Forensic Medicine \& Toxicology ${ }^{3}$, Dept. of \\ Pharmacology 4 , Dept. of Microbiology ${ }^{5}$, \\ S.S. Institute of Medical Sciences and Research Centre, Karnataka (India)
}

\begin{abstract}
Aims : Polycystic ovarian syndrome (PCOS) is one of the common Gynaecological condition of diverse etiology $30 \%$ of the infertile women have anovulation due to polycystic ovarian disease, $20-30 \%$ of them have hyperandrogenemia and hyperprolactenemia.'
\end{abstract}

Method : An explorative type of hospital based study of 102 patient, during a 2 year period (Oct. 2008 Oct. 2010) was done. Of which 75 (73.52\%) were married women and 27 (26.47\%) were unmarried women with varied symptomatology.

Results: $67.6 \%$ of patients were in the age group 21-30 years. Ovulation induction was done in all the infertile group, an ovulation induction rate of $88.40 \%$ was achieved and of these 21 (34.42\%) conceived, others on follow up.

Of the unmarried women, all of whom had menstrual irregularities along with obesity (51.85\%) and hirsutism (48.14\%), after treatment $66.66 \%$ had an improvement in their symptoms, other still on follow up.

Conclusion: This study demonstrates the various presentations either single or in combination and their response to various medical and surgical management.

There should be a relational approach to therapy; treatment of polycystic ovarian syndrome should be tailored according to the major symptoms of the patients.

\section{Introduction}

PCOS is an incompletely understood enigmatic disorder of heterogeneous nature and is the commonest endocrinopathy of the reproductive age. PCOS starts appearing from $15-25$ years of age and it may take years, for its clinical presentation to appear. It is diagnosed in $5-10 \%$ of women between adolescence and menopause. ${ }^{2}$

It has an autosomal dominant inheritance ${ }^{3}$ with great phenotypic variability presenting with infertility (mean incidence 74\%), menstrual irregularity (mean incidence of DUB 29\%, and amenorrhea 51\%) and androgen excess (mean incidence of hirsutism 69\% while of virilization being $21 \%$ ), ${ }^{4}$ along with serious long term consequences like endometrial carcinoma, obesity, hyperinsulinsim, cardiovascular risks, bone disease etc., leaving their impact on quality of life, morbidity and mortality. ${ }^{3}$

The diagnosis of PCOS depends on confirming the presence of hyperandrogenism with elevated serum, testosterone and an elevated LH: FSH ratio. Either or both of these may be found in $60-70 \%$ of patients, with greatest sensitivity and specificity. ${ }^{2}$

Ultrasound is now considered as the gold standard in the evaluation of infertility. ${ }^{1}$ Diagnostic laparoscopy

\footnotetext{
Correspondence

Dr. Gayatri Linganagouda Patil MD, MRCOG, DNB, PGDMLE

Associate Prof, Dept of Obs / Gyn

S.S. Institute of Medical Sciences \& Research Centre,

Davangere - 577005, Karnataka (India).

Phone: 9886733535

E-mail: ptlgayatri@yahoo.co.in
} 
with or without ovarian drilling is used as a second line of management in cases of failed induction or in unexplained infertility and also to assure tubal patency. ${ }^{5}$

The purpose of this study is to know about the clinical course and outcome of polycystic ovarian disease.

\section{Aims and Objectives}

Aim is to find out the various presentations either single or in combination and their response to the various medical and surgical management.

1. To study the clinical presentations and hormonal imbalances in these women with polycystic ovarian disease.

2. Sonological evaluation of women with polycystic ovarian disease and its correlation with hormonal values.

3. Laparoscopic evaluation and/or ovarian drilling of infertile women with polycystic ovarian disease, after failed ovulation induction.

4. To study the outcome of all the modalities of treatment particularly in hirsutism and infertility.

\section{Methods}

\section{Study Design and Study Population}

Type of study: Explorative type of hospital based study.

Place of study: All the women attending the Gynaecology out patient department at S.S. Institute of Medical Science and Research Centre with complaints of hirsutism, infertility and menstrual irregularities were studied.

\section{Study Eligibility Criteria}

Sample size of duration of study: The criteria was that a total of about 100 patients or the number of patients with polycystic ovarian disease in a period of 2 years from Oct. 2008 to Oct. 2010 were recruited for the purpose of the study. The related data were collected by detailed history and clinical examination.

Inclusion Criteria: All patients with polycystic ovarian disease irrespective of age and body weight.

Exclusion Criteria: Patients were later excluded if the cause of hirsutism, infertility and obesity was of non-ovarian origin.

Study Procedure: In the Out Patient Clinic, an informed consent was taken, and patients were recruited for the study. Then a detailed history and general examination was done.

A diagnosis of PCOS was made based on the relevant history, clinical findings and confirmed by relevant investigations which included basic investigations like hemoglobin levels, urine routine and random blood sugar estimations, hormonal profile testosterone, follicle stimulating hormone, leutinising hormone, prolactin, thyroid stimulating hormone levels were assessed within 3 days of menstruation and an ultrasound examination for prediction of ovulation was done around the time of ovulation.

The semen analysis of the husband, if the patient presented with infertility was done to rule out an associated male factor as a cause of infertility.

For those who desired to conceive, ovulation induction with clomiphene citrate was the initial choice, with 50 $\mathrm{mg}$ /day for 5 days, starting on $\mathrm{D}_{2}$ of cycle. Follicular study was done on $10^{\text {th }}, 12^{\text {th }}$ and $14^{\text {th }}$ day of the cycle. To improve the mid cycle LH surge, Inj HCG (5000 $-10000 \mathrm{u}$ ) im was given around the time at which the follicle size was 18-20 mm and HCG administered patient's required intense follow-up for any evidence of ovarian hyperstimulation symptoms.

Patients with hirsutism were more resistant to $\mathrm{CC}$ alone and so dexamethasone was added at a low dose of 0.5 $\mathrm{mg}$, orally and those with high prolactin levels were given bromocriptine starting at a usual dose of 2.5 $\mathrm{mg}$ /day, orally for 2 months along with clomiphene. A repeat hormonal assay was done after 2 months of treatment to see for the response.

If all the above combinations failed, then preparations of gonadotropins (HMG) was given for follicle stimulation beginning by 7-14 days of the cycle with continuous daily intramuscular injections beginning with $75 \mathrm{u}$ /day. Serum estradiol measurement and ultrasound monitoring were needed during the therapy to look for adverse reactions. HMG was combined with clomiphene in a few patients.

If still the follicular development was unsatisfactory then treatment was with purified FSH preparations with a dose of $1 \mathrm{amp} /$ day (75 iu FSH) intramuscularly was given and monitoring resumed and HCG timed once the follicle was $15-18 \mathrm{~mm}$.

Metformin was added to clomiphene if the patient was obese and had insulin resistance. The dose was $500 \mathrm{mg}$ tid for a period of 3-4 months. Ultimately when the medical line of treatment was unsuccessful to achieve conception diagnostic hystero laparoscopy with chromopertubation was planned, with or without ovarian drilling under general anaesthesia. Following laparoscopy, the next cycle was started with clomiphene at $50 \mathrm{mg} /$ day dose. Conception rates did improve.

Conceived women were followed up to know the outcome of pregnancy. 
In the other group of unmarried women with polycystic ovarian disease, apart from a general advise of weight reduction, they were started on either oral contraceptives with or without Finasteride (Once a day) and Aldactone (Once a day) for a period of 3 to 6 months and then evaluated for the improvement of symptoms being regularization of cycles, decreasing hirsutism scores and reduction in body weight. A repeat hormonal assay was done 3 months later for the response to the treatment.

\section{Results}

Of the 102 patients with PCOS, $67.6 \%$ comprised of group of 21-30 years of which 75 women (73.52\%) were married and $27(26.47 \%)$ were unmarried women (Table 1).

Infertility was their chief complaint accounting to $73.5 \%$. Along with infertility majority of women had menstrual irregularities $(74.66 \%)$ followed by obesity $(46.07 \%)$ as their associated complaints. Virilisation presented in only $1.96 \%$ of these cases.

All the unmarried women had history of menstrual irregularities, $(100 \%)$ followed by obesity in $51.85 \%$ and hirsutism in $48.14 \%$ of patients.

Of the total 102 patients, 20 of them $(19.60 \%)$ had glucose intolerance, serum LH was raised in 57 (55.88\%) of patients, serum FSH was significant in 16 of patients, but serum LH:FSH ratio of 2:1 was seen in $32(31.37 \%)$ of the study group.

Hyperandrogenemia was seen in $88(86.27 \%)$ patients, $23(18.62 \%)$ of cases had hyperprolactenemic and serum TSH was raised in $07(6.86 \%)$ and $2(2.66 \%)$ had a luteal phase defect as detected by the 21 day progesterone levels.

Tran Abdominal Ultrasound Scan was done in 91(89.21) of the total 102 women. Typical PCO picture was seen in 79 (86.81) and normal ovaries was seen in $12(13.18)$.

But out of the 75 married women, typical PCO picture seen in 63 (84.00), normal ovaries seen in 12 (16.00). However Serum FSH ( $>10.5 \mathrm{Iu} / \mathrm{L}) 13$ (17.33), Serum LH ( $>6.5 \mathrm{Iu} / \mathrm{L}) \quad 44$ (58.66), Serum LH/FSH ratio (> $2: 1) 26$ (34.66), Serum testosterone $(>10 \mathrm{mg} / \mathrm{ml}) 46$ (61.33)

The typical picture of polycystic ovaries was seen in 79 cases $(86.81 \%)$ and the findings of normal ovaries was seen in 12 cases $(13.18 \%)$ in total. However out of 75 infertile women, typical USG PCO picture was seen in 63 (84.00) whereas normal ovaries was seen in $12(16.00)$
Ultrasound was considered as the gold standard for the diagnosis of polycystic ovaries. It was done in $89.21 \%$ of cases, not done in 11 patients $(10.78 \%)$ who belonged to the unmarried group.

Of the 30 patients who underwent diagnostic laparoscopy, $26(86 \%)$ had polycystic ovaries and 3 $(10 \%)$ had normal ovaries, $1(3 \%)$ had the severe form of polycystic ovaries.

Of the 21 patients who conceived, 9 of them (42.85\%) had full term deliveries, $2(9.52 \%)$ underwent an emergency LSCS for fetal distress. While the abortion rate was (14.28\%) [Missed abortion 2(9.52), Inevitable abortion 1(4.76)]. Ongoing pregnancy is 7 (33.32\%) of whom $2(9.52 \%)$ have already crossed the period of viability $(<28$ weeks).

However, there was no incidence of either ectopic pregnancy or of multiple gestations in this study.

Table 5 shows the various combinations used, CC was used with HCG, b-CRIP, Dexamethasone, Eltroxin, Metformin, HMG, FSH either singly or in a combination therapy depending on the needs of the patient. In the unmarried group, OC'S were used either singly or in combination with Finast and/or Aldactone depending on the symptomatology and clinical findings. It is sure from the above table that there is no single mode of approach and treatment of polycystic ovarian disease but it is simply a multimodality approach.

Of the $27(26.47 \%)$ unmarried women included in this study, almost all of them had presented with menstrual irregularities, and after treatment with OC pills, had an improvement in regularization of cycles in 9 patients $(33.33 \%)$. Treatment with tablet Aldactone and Finasteride and weight reduction there was an average improvement in $14-18 \%$ of these patients after 3-6 months of treatment, and $33.33 \%$ of these patients are still on follow up.

So in this study of 75 infertile patients, in whom 69 $(92.0 \%)$ had ovulation induction of whom $61(88.40 \%)$ ovulated and $21(34.42 \%)$ of them conveived, with a total unexplained infertility $4(5.33 \%)$ rate and incidence of mild OHSS on treatment occurred in 2 $(2.89 \%)$ of cases, while the others $48(69.56 \%)$ are still on follow up.

Of the 75 infertility patients comprising of both primary and secondary cases, $74.66 \%$ mainly had menstrual irregularities followed by obesity in $62.66 \%$ of these cases, on hormonal assay, a significant LH:FSH ratio of $\geq 2: 1$ was seen in only $34.66 \%$ cases but a raised 
serum testosterone value definitely correlated with the symptoms in $61.33 \%$ of these cases. And so serum testosterone can be used as a definitive hormonal test for diagnosing PCOS.

In this group, carbohydrate intolerance, hyperprolactinaemia and hypothyroidism were present in $19 \%, 21 \%$ and $9 \%$ respectively.

$84 \%$ of the infertility group (75) had the typical PCO picture on transabdominal scan. A significant serum LH:FSH was found in only $34.66 \%$ of this group, but $61.33 \%$ of the infertile patients had a high serum testosterone value. It could be concluded that scan picture correlated with the serum testosterone value and is more definitive in the approach towards the disease.

\section{Statistical Analysis}

Results of the 75 infertile patients, there was a significant difference between medical and surgical groups with respect to LH:FSH ratio $(p<0.01)$, in cases with high LH:FSH ratios surgical mode of treatment with ovarian drilling would be a better choice if the patient fails to respond to medical therapy.

Secondary, there was a significant difference between medical and surgical groups when associated with high testosterone values $(\mathrm{p}<0.05)$ and medical therapy for infertility fared better.

Table 1. Chief Complaints

\begin{tabular}{lcc}
\hline Presenting complaints & $\begin{array}{c}\text { Married women } \\
\text { Frequency (\%) }\end{array}$ & $\begin{array}{c}\text { Unmarried women } \\
\text { Frequency (\%) }\end{array}$ \\
\hline Infertility & $75(73.50)$ & - \\
Primary infertility & $57(78.66)$ & - \\
Secondary infertility & $18(21.33)$ & - \\
Hirsutism & $26(25.49)$ & $13(48.14)$ \\
Menstrual irregularities & $56(74.66)$ & $27(100)$ \\
Obesity & $47(46.07)$ & $14(51.85)$ \\
Early virilisation & $02(01.96)$ & - \\
\hline
\end{tabular}

\section{Table 2. Investigations}

\begin{tabular}{lcc}
\hline Investigation & Frequency (\%) & $\begin{array}{c}\text { Out of 75 infertile women } \\
\text { n(75) }\end{array}$ \\
\hline Random blood sugar $(>120 \mathrm{mg} / \mathrm{dl})$ & $20(19.60)$ & \\
Serum luteinising hormone $(>6.7 \mathrm{IU} / \mathrm{L})$ & $57(55.88)$ & $44(58.66)$ \\
Serum Follicle stimulating hormone $(>10.5 \mathrm{IU} / \mathrm{L})$ & $16(15.68)$ & $13(17.33)$ \\
Serum LH : FSH ration $(\geq 2: 1)$ & $32(31.37)$ & $26(34.66)$ \\
Serum testosterone $(>10 \mathrm{ng} / \mathrm{ml})$ & $88(86.27)$ & \\
Serum prolactin $(>20 \mathrm{pg} / \mathrm{ml})$ & $23(18.62)$ & \\
Serum TSH $(>6.5 \mu \mathrm{u} / \mathrm{ml})$ & $07(6.86)$ & \\
21 days progesterone $(<10 \mathrm{ng} / \mathrm{ml})$ & $02(2.66)$ & \\
\hline
\end{tabular}

Table 3. Work up Infertility Group

\begin{tabular}{lc}
\hline Correlations & Frequency \\
\hline Menstrual irregularities & $56(74.66)$ \\
Obesity & $47(62.66)$ \\
Hirsutism & $26(34.66)$ \\
Virilisation & $02(2.66)$ \\
Serum LH $(>6.7 \mathrm{Iu} / \mathrm{L})$ & $44(58.66)$ \\
Serum FSH $(>10.5 \mathrm{Iu} / \mathrm{L})$ & $13(17.33)$ \\
Serum LH:FSH $(\geq 2: 1)$ & $26(34.66)$ \\
Serum testosterone $(>10 \mathrm{mg} / \mathrm{dl})$ & $46(61.33)$ \\
Serum prolactin $(>10 \mathrm{pg} / \mathrm{ml})$ & $16(21.33)$ \\
Serum TSH $(>6.5 \mu \mathrm{u} / \mathrm{ml})$ & $07(9.33)$ \\
Random blood sugars $(>120 \mathrm{mg} / \mathrm{dl})$ & $20(19.60)$ \\
\hline
\end{tabular}

Table 4. Findings on Diagnostic laparoscopy

\begin{tabular}{lccc}
\hline Findings & $\begin{array}{c}\text { Frequency } \\
(\mathbf{n}=\mathbf{3 0})\end{array}$ & $\begin{array}{c}\text { Ovarian drilling } \\
\text { done }\end{array}$ & not done \\
\hline Polycystic ovaries & $26(86.66)$ & & \\
Hyperthecosis & $01(3.33)$ & $27(90)$ & \\
Normal ovaries & $03(10.00)$ & & $03(10)$ \\
Tubal patency & $30(100)$ & & \\
\hline
\end{tabular}


Table 5. Other treatment modalities

\begin{tabular}{lc}
\hline Other modalities of treatment & Frequency \\
\hline CC + B - Crip + HCG & 04 \\
CC + Dexa + B-crip & 04 \\
CC + HCG + Eltroxin & 0 \\
CC + HCG & 17 \\
CC + Metformin & 06 \\
CC + FSH + HMG & 01 \\
Combination therapy & 01 \\
CC + Progesterone supplements & 2 \\
OC alone & 1 \\
Tab Finast + Tab Aldactone & 8 \\
OC + Finast + Aldactone & 5 \\
OC + Finast & 2 \\
OC + Aldactone & 4 \\
Tab Finast & 4 \\
Tab Aldactone & 3 \\
CC + Dexamethasone & 12 \\
CC + B-crip & 23 \\
CC + HMG & 01 \\
\hline
\end{tabular}

Table 6. Outcome of 75 infertile women

\begin{tabular}{lc}
\hline Outcome & $\begin{array}{c}\text { Frequency } \\
(\mathbf{\%})\end{array}$ \\
\hline Ovulation induction done in & $69(92.0)$ \\
Patients who ovulated & $61(88.40)$ \\
No. of women who conceived & $21(34.42)$ \\
Unexplained infertility & $04(5.33)$ \\
Mild OHSS & $02(2.89)$ \\
On follow up & $48(69.56)$ \\
\hline
\end{tabular}

\section{Discussion}

Key findings of the results are as follows:

- In our study, $81.37 \%$ presented with menstrual irregularities, with polycystic ovaries on scan is $86 \%$ and $92 \%$ of these women had atleast one hormonal abnormality to support the diagnosis. It can be compared with the incidence of $75 \%, 56.75 \%$ and $93 \%$ respectively, reported by Adams et al ${ }^{1}$.

- Our study results reveal that $26(34.56 \%)$ of the infertile patients with abnormal LH/ FSH ratio, only $21(80.76 \%)$ had typical polycystic ovarian morphology on ultrasound and $5(19.23 \%)$ had normal ovaries on scan. Ardaens et al in their study have showed that transvaginal scan is more sensitive in diagnosing polycystic ovarian when compared to a transabdominal scan ${ }^{6}$.

- Elevated LH levels was seen in $58.66 \%$ FSH in $17.35 \%$ and testosterone in $61.33 \%$ and LH/ FSH ratio $>2: 1$ with $p$ value $<0.01$ are similar to results of the study conducted by Robinson et $\mathrm{al}^{7}$.

- Studies have documented that a ratio of 3:1 serves as a useful guideline ${ }^{8}$.

- In our study ovulation induction was achieved in $88.40 \%$ of which $41.93 \%$ conceived with an average follicular size $19 \times 21 \mathrm{~mm}$ and this correlated with Rajan et al, who had an ovulation rate of $86 \%$, conception rate of $49 \%$ and a follicular size of $23 \times 16 \mathrm{~mm}^{9}$.

- Of the women $(34.42 \%)$ who conceived during our study, an overall abortion rate of $13 \%$, which correlated with the results quoted by Campo et $\mathrm{al}^{10}$.

\section{Conclusion}

In polycystic ovarian syndrome there is no single test as the gold standard to prove the disease, as it is a cohort of abnormalities requiring a multi modality approach towards the disease.

In this study, there was an overall improvement of symptoms in $66.66 \%$ of unmarried women with PCOD, after appropriate treatment.

In the infertility group of patients, the ovulation rate of $88.40 \%$, pregnancy rate of $34.43 \%$ and the pregnancy rate after laparoscopy / drilling of $26.7 \%$ was acceptable statistically.

Statistical analysis also showed a significant difference between the medical and surgical modalities of management with respect to a high LH:FSH ratio and testosterone values.

The proper selection of the patients, intense monitoring and early detection of complications go a long way towards the success of conception.

\section{References}

1. Adams J, Polson DW, Franks S. Prevalence of polycystic ovaries in women with anovulation and idiopathic hirsutism. Br Med J, 1986; 293:355-358.

2. Robisnson $\mathrm{S}$, et al. Which hormone tests for the diagnosis of polycystic ovary syndrome? Bri J Obstet and Gynaecol 1992; 99:232-238.

3. Campo, Sebastiano. Ovulatory cycles, pregnancy outcome and complications after surgical treatment of polycystic ovary syndrome. Obstet Gynaecol Survey 1998; 53(5):297-305.

4. Shah D, Agarwal S. Polycystic ovarian syndrome in the Adolescent girl. J Obstet Gynaecol India 1999; 49(5):46-48.

5. Rajan R. Endocrinology of PCOs: clinical presentation. Chap. 22, Postgraduate 
Reproductive Endocrinology, Jaypee Publishers, New Delhi, $4^{\text {th }}$ edition 1997. Pg.325.

6. Attaran M. Polycystic ovarian syndrome, Cleveland clinic, center for continuing education 2008; 1-8.

7. Al-Ojaimi EH. Laparoscopic ovarian drilling for polyeystic ovarian syndrome in clomiphene resistant women with anovulatory infertility. Bahrian Med Bull 2003; 25(2):58-63.

8. Rogerio LA. The role of neurotransmitters and opioids in polycystic ovarian syndrome. Endocrinol Metabol Clin North Am 1988; 17(4):667.

9. Gloria BA. Polycystic Ovary Syndrome: Metabolic challenges and new treatment options. Am J Obstet Gynaecol 1998; 179(6)2:S87-S113.

10. Ardaens et al. Polycystic ovarian disease: contribution of vaginal endosonography and reassessment of ultrasonic diagnosis. Fertil Steril 1991; 55(6):1062-1068. 